Murray B. Isman*

\title{
Bioinsecticides based on plant essential oils: a short overview
}

https://doi.org/10.1515/znc-2020-0038

Received February 21, 2020; revised March 22, 2020; accepted April 6, 2020

\begin{abstract}
Interest in the discovery and development of plant essential oils for use as bioinsecticides has grown enormously in the past 20 years. However, successful commercialization and utilization of crop protection products based on essential oils has thus far lagged far behind their promise based on this large body of research, most notably because with the exceptions of the USA and Australia, such products receive no special status from regulatory agencies that approve new pesticides for use. Essential oil-based insecticides have now been used in the USA for well over a decade, and more recently have seen use in the European Union (EU), Korea, and about a dozen other countries, with demonstrated efficacy against a wide range of pests and in numerous crop systems. For the most part these products are based on commodity essential oils developed as flavor and fragrance agents for the food and cosmetic industries, as there are formidable logistic, economic, and regulatory challenges to the use of many other essential oils that otherwise possess potentially useful bioactivity against pests. In spite of these limitations, the overall prospects for biopesticides, including those based on essential oils, are encouraging as the demand for sustainably-produced and/or organic food continues to increase worldwide.
\end{abstract}

Keywords: efficacy; insect toxicology; terpenoids.

\section{Introduction}

Plant essential oils have a long history of human use, principally as flavoring and fragrance agents founded in traditional uses of aromatic plants as culinary herbs and spices. More recently their value in human medicine, as phytopharmaceuticals and in aromatherapy, has increased their range of uses, and these, together with their widespread use in foods and beverages has defined their relative

*Corresponding author: Murray B. Isman, Faculty of Land and Food Systems, University of British Columbia, Vancouver, BC V6T 1Z4, Canada, E-mail: murray.isman@ubc.ca safety through both empirical practice and more rigorous experimental evaluation in animal models. Considerable recent attention on essential oils has focused on their broad range of bioactivities on pests and disease-causing organisms and thus their potential use as alternatives to synthetic chemical pesticides for crop protection and in other pest management contexts.

This expansion of potential uses of essential oils has fueled a massive increase in academic and industrial research on the biological activities of these plant-derived materials. For example, a bibliometric analysis of published research on botanical insecticides [1] indicates that roughly $25 \%$ of all such research since 2010 involved essential oils. Research into essential oils has advanced in large part owing to their ease of preparation and analysis relative to other types of plant extracts, and their relatively well-known chemistry with many major terpenoid constituents commonly shared between plant taxa.

\section{Essential oils as pesticides}

Commercialization of bioinsecticides, starting about 20 years ago in the USA, was greatly facilitated by the exemption of certain essential oils and a few of their major constituents as pesticidal active ingredients, from the normal regulatory approval process required for other pesticides [2]. This allowed these products to reach the market in far less time, and with enormous cost savings relative to conventional registered pesticides. The specific list (Federal Insecticide, Fungicide and Rodenticide Act [FIFRA] List 25b) included some commodity essential oils including oils of cedarwood, cinnamon, citronella, cloves, garlic, geranium, lemongrass, peppermint, rosemary, sesame, and thyme.

Today there are a number of insecticides in production that contain rosemary, peppermint, cinnamon, clove, eucalyptus, and thyme oils (and others), either singly or in combination as their active ingredients (Table 1). Some products contain mixtures of oils while others utilize a single essential oil, or even a single terpenoid constituent (8, Figure 1). The best example of the latter is the product Prev-Am ${ }^{\circledR}$, (Oro Agri, Cape Town, South Africa) containing $5-6 \%$ orange oil as the active ingredient. The composition of orange oil is dominated $(>90 \%)$ by $d$-limonene, 
Table 1: Common essential oils used in pesticide formulations.

\begin{tabular}{lll}
\hline Plant essential oil & Botanical source (species, family) & Major constituent(s) (\% by weight) [ref] \\
\hline Cinnamon oil & Cinnamomum verum (Lauraceae) & Cinnamaldehyde (55-76), eugenol (5-18) [3] \\
Citronella oil & Cymbopogon winterianus (Poaceae) & Citronellal (27-33), citronellol (10-16), geraniol (24-40) [3] \\
Clove oil & Syzygium aromaticum (Myrtaceae) & Eugenol (89) [3] \\
Eucalyptus oil & Eucalyptus globulus (Myrtaceae) & 1,8 -Cineole (67-84) [3] \\
Lemongrass oil & Cymbopogon citratus (Poaceae) & Geranial (34-45), neral (5-51), myrcene (9-25) [3] \\
Mint oil & Mentha spp. (Lamiaceae) & Menthol (30-55), menthone (10-40) [3] \\
Orange oil & Citrus sinensis (Rutaceae) & $d$-Limonene (91-97) [3] \\
Peppermint oil & Mentha piperita (Lamiaceae) & Menthol (7-48), menthone (20-46) [4] \\
Rosemary oil & Rosmarinus officinalis (Lamiaceae) & $1,8-$ Cineole (52), $\alpha$-pinene (10), camphor (9), $\alpha$-pinene (8) [5] \\
Tea tree oil & Melaleuca alternifolia (Myrtaceae) & Terpinen-4-ol (35-48), $\alpha$-terpinene (14-28) [6] \\
Thyme oil & Thymus vulgaris (Lamiaceae) & Thymol (50), $p$-cymene (33) [7] \\
\hline
\end{tabular}
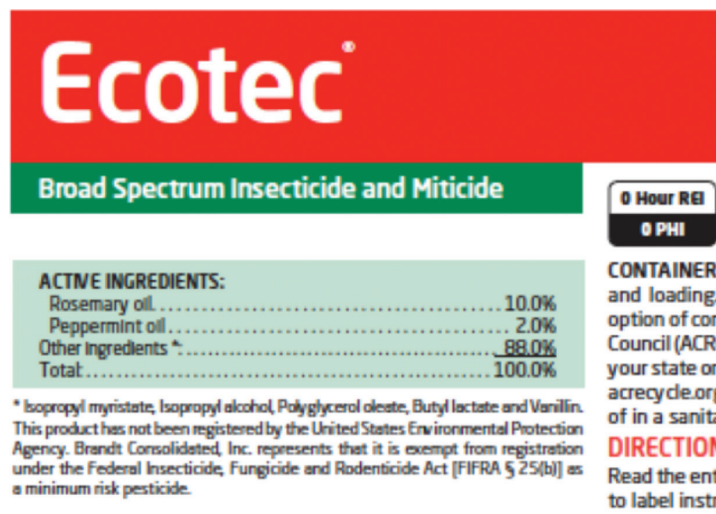

$$
\text { OPHI }
$$

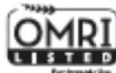

CONTAINER DISPOSAL: Triple rinse (or equivalent) during mixing and loading. Recycling decontaminated containers is the best option of container disposal. The Agricultural Container Recycling Council (ACRC) operates the national recycling program. To contact your state or local ACRC recycler, visit the ACRC web page atwww. acrecycleorg. Decontaminated containers may also be disposed of in a sanitary landfill. DIRECTIONS FOR USE

Read the entire label before using this product. Use only according to label instructions

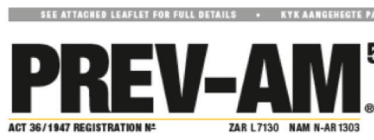

CONTACT INSECTICIDE AND FUNGICIDE

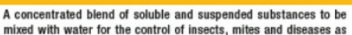
mixed with water for the cont
indicated for specified crops.

KONTAK INSEK- EN SWAMDODER

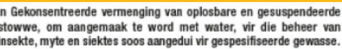

insekte, myte en siektes soos angedui vir gespesifiseerde gewasse.

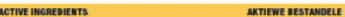

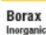

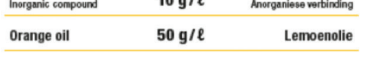

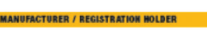

Oro Agri SA (Pty) Ltd.

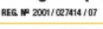

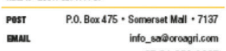
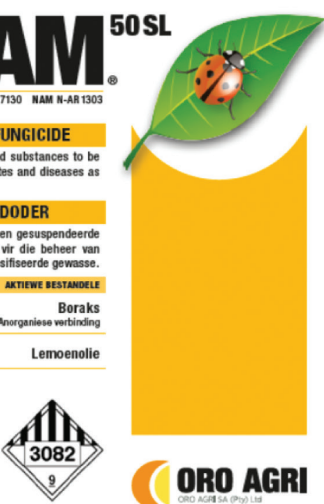

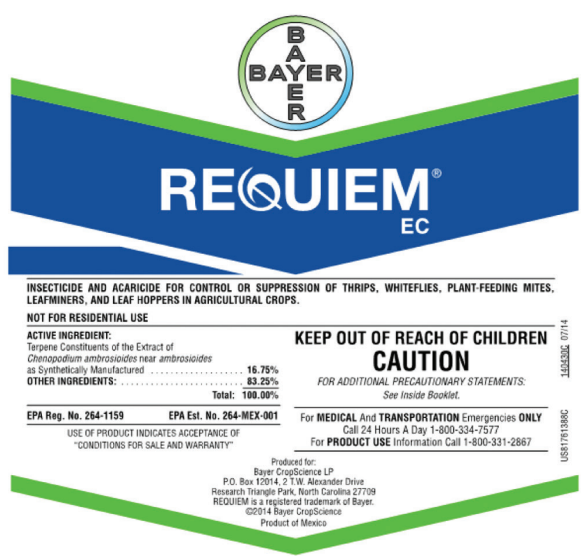

Figure 1: Two commercial bioinsecticides based on plant essential oils, and one (Requiem ${ }^{\circledR}$ ) based on a blend of synthetic terpenoids.

and other pesticide products list this compound itself as the active ingredient. For some other essential oils, insecticidal activity can be attributed to the dominant constituent, for example, thymol in thyme oil or citral in lemongrass oil [7].

Other essential oils are more chemically complex. Rosemary oil often contains up to 10 major constituents, but an initial attempt to correlate toxicity to the cabbage looper (Trichoplusia ni, Noctuidae) with chemical composition produced equivocal results [5]. A more detailed investigation revealed that almost all of the toxicity could be attributed to the synergistic interaction of camphor and 1,8-cineole, and that the synergy was a consequence of enhanced penetration of camphor in the 
presence of 1,8-cineole [8]. Synergy among terpenoids in essential oil as insecticides appears to be a relatively common phenomenon [9].

\section{Mechanisms of action}

The rapid action of essential oils on many pest species points to a site of action in the insect nervous system. Indeed a number of different putative receptors for essential oil terpenoids (and biogenically-related phenols) have been identified, including receptors for octopamine, gamma-aminobutyric acid (GABA)-gated chloride channels, and nicotinic acetylcholine, as well as for acetylcholine esterase [10]. To date the evidence for interference with octopamine receptors is perhaps the most convincing, but the small size and wide range of chemical structures among essential oil terpenoids suggests that multiple sites and mechanisms of action can be affected simultaneously.

While oils tend to be readily absorbed by insects on contact, the volatile nature of essential oils and their constituents make many of them effective fumigants in closed spaces. Indeed there is a plethora of scientific literature documenting the efficacy of essential oils as stored grain protectants [11]. Behavioral effects on pests may also play a role in crop protection on horticultural crops; when sprayed on plants essential oils tend to have minimal residual action as contact insecticides, but there is evidence in the field that pests may be deterred or repelled for a much longer time following application [12]. Nanoformulations and microencapsulation technologies are being deployed to provide slow release of terpenoids, enhancing efficiency under field conditions $[13,14]$. Certain essential oils, notably citronella oil, has seen use as personal protectants against mosquitoes and other blood-feeding arthropods, but products of this type have suffered from very limited residual action thus far. Formulation technologies that reduce volatilization from surfaces (including human skin or clothing) could well enhance this particular use of essential oils.

\section{Advantages of essential oils as bioinsecticides}

The long history of human use of essential oils as flavors and fragrances, and thus their familiarity, should enhance their public acceptance as pesticides. For many of the commodity essential oils, their safety to humans (based on other aforementioned uses) is relatively well documented and understood. Their low persistence under field conditions favors their compatibility with biological control agents and pollinators, and they tend to be relatively nontoxic to birds, fish, and other wildlife. Likewise, their low persistence enhances farm worker safety (no field re-entry limitations) and suggests little or no residues on foods. Products containing mixtures of essential oils, or chemically complex oils may prove durable in use as the target pests are less likely to evolve resistance than to products containing a single active ingredient. Finally, certain commodity oils are inexpensive in bulk quantities, making bioinsecticides based on these active ingredients cost competitive, at least at current prices.

\section{Disadvantages of essential oils as bioinsecticides}

All oils, irrespective of origin, can be phytotoxic if applied to plants at high concentrations. Essential oils are no different. Compared to conventional insecticides, and some other botanicals, essential oil-based insecticides are considerably less active - often by $2-4$ orders of magnitude - and therefore have to be used at relatively high concentrations, often in the range of $0.5-1.5 \%$ in final dilution. For any given crop application, products must be empirically tested to identify the risks of phytotoxicity. And while little or no residues are expected on food following application of essential oil-based pesticides, the potential influence or impact of the practice on organoleptic quality of the resulting foods has not been investigated in much detail to date.

Looking forward, pesticides based on essential oils run the risk of becoming victims of their own success: if widely adopted by farmers, the volumes needed might eventually become unavailable from essential oil producers at competitive prices, especially if these highvolume agricultural uses compete with availability of the same essential oils used for higher value products such as pharmaceuticals and perfumes. Those in the essential oil industry already recognize that as uses expand, the plant biomass used to produce certain oils may become in short supply, making their use cost prohibitive. To mitigate this risk, several alternative means of producing terpenoid natural products are being explored, from total synthesis to yeast biocatalysis and fermentation technologies [15]. The utility of terpenoids from sources other than essential oils as active ingredients in 
a bioinsecticide has already been proven by the commercial success of Requiem ${ }^{\circledR}$ - a mixture of three synthetically-produced monoterpenes that together simulate the major constituents of the essential oil from the wormwood Chenopodium ambrosoides nr. Ambrosoides [12].

\section{Conclusion}

Bioinsecticides based on plant essential oils have already become established in several important jurisdictions, and while small compared to markets for microbials and other biopesticides, these products are expanding to other countries and sectors. In large part this is owing to growing public demand for pest management products with fewer human health and environmental impacts, both in food production ("organic" and "sustainably-produced") and in public health and urban pest management [16]. The continuing loss of conventional pesticides through regulatory action or loss of efficacy from increasing pest resistance is also creating opportunities for essential oil-based pesticides.

Disclaimer: The author conducted over 20 years of research on the bioactivities of plant essential oils and their constituents in insects, and the subsequent development of commercial bioinsecticides. Many of the statements in this paper represent his perspectives and opinions and reflect his experiences from this research and industry collaborations over this period.

\section{References}

1. Isman MB, Grieneisen MJ. Botanical insecticide research: many publications, limited useful data. Trends Plant Sci 2014;19:140-5.

2. Isman MB, Miresmailli S, Machial C. Commercial opportunities for pesticides based on plant essential oils in agriculture, industry and consumer products. Phytochem Rev 2011;10:197-204.
3. Nollet LM, Rathore HS, editors. Green pesticides handbook. Essential oils for pest control. Boca Raton, FL: CRC Press, 2017.

4. Leung AY. Encyclopedia of common natural ingredients used in food, drugs and cosmetics. New York, NY: John Wiley \& Sons, 1980.

5. Isman MB, Wilson JA, Bradbury R. Insecticidal activities of commercial rosemary oils (Rosmarinus officinalis) against larvae of Pseudaletia unipuncta and Trichoplusia ni in relation to their chemical compositions. Pharmaceut Biol 2008;46:82-7.

6. International Organization for Standardization (ISO). Essential oil of Melaleuca, terpinen-4-ol type (Tea Tree oil): ISO 4730:2017 (iso.org/standard/69082.html).

7. Tak J-H, Jovel E, Isman MB. Contact, fumigant and cytotoxic activities of thyme and lemongrass essential oils against larvae and an ovarian cell line of the cabbage looper, Trichoplusia ni. J Pest Sci 2016;89:183-93.

8. Tak J-H, Isman MB. Enhanced cuticular penetration as the mechanism of synergy of insecticidal constituents of rosemary essential oil in Trichoplusia ni. Sci Rep 2015;5:12690.

9. Tak J-H, Isman MB. Penetration-enhancement underlies synergy of plant essential oil terpenoids as insecticides in the cabbage looper, Trichoplusia ni. Sci Rep 2017;7:42432.

10. Isman MB, Tak J-H. Inhibition of acetylcholinesterase by essential oils and monoterpenoids: a relevant mode of action for insecticidal essential oils? Biopestic Int 2017;13:71-8.

11. Rajendran S, Sriranjini V. Plant products as fumigants for storedproduct insect control. J Stored Prod Res 2008;44:126-35.

12. Isman MB. Commercial development of plant essential oils and their constituents as active ingredients in bioinsecticides. Phytochem Rev, in press (DOI: 10.1007/s11101-019-09653-9). [Epub ahead of print].

13. De Oliveira JL, Ramos Campos EV, Bakshi M, Abhilash PC, Franceto LF. Application of nanotechnology for the encapsulation of botanical insecticides for sustainable agriculture: prospects and promises. Biotechnol Adv 2014;32:1550-61.

14. Benelli G, Pavela R, Maggi F, Petrelli R, Nicoletti M. Commentary: making green pesticides greener? The potential of plant products for nanosynthesis and pest control. J Clust Sci 2017;28:3-10.

15. Forti L, Di Mauro S, Cramarossa MR, Filipucci S, Turchetti B, Buzzini P. Non-conventional yeast whole cells as efficient biocatalysts for the production of flavors and fragrances. Molecules 2015;20:10377-98.

16. Marrone PG. Pesticidal natural products - status and future potential. Pest Manag Sci 2019;75:2325-40. 